\title{
LIVROS PARA A PRIMEIRA INFÂNCIA: ANALISANDO OS ACERVOS DO PROGRAMA NACIONAL BIBLIOTECA DA ESCOLA
}

\author{
Claudia Leite Brandão ${ }^{1}$, Sílvia de Fátima Pilegi Rodrigues ${ }^{2}$, Renata Junqueira de Souza ${ }^{3}$ \\ ${ }^{1}$ Universidade Estadual Paulista - UNESP, ${ }^{2}$ Universidade Federal de Mato Grosso - UFMT, ${ }^{3}$ Universidade Estadual \\ Paulista - UNESP, Programa de Pós-Graduação em Educação, Presidente Prudente, SP. E-mail: \\ cau_brandao@live.com.
}

\section{RESUMO}

Este estudo objetivou compreender o processo de aquisição e distribuição dos livros de literatura para a Educação Infantil, por meio do Programa Nacional Biblioteca da Escola, apresentando dados sobre funcionamento e recursos investidos pelo MEC. Para tanto, partiu-se da pesquisa de abordagem quanti-quali, de cunho documental e bibliográfico. O Programa foi instituído no ano de 1997, para promover acesso e incentivar à leitura de alunas/os e professoras/es. Durante os dezoito (18) anos de existência do PNBE, a Educação Infantil foi contemplada em quatro edições (2008, 2010, 2012 e 2014), adquirindo 20.998 .568 livros com um investimento de R\$ 96.009.536,40. Por meio das obras de literatura infantil, a criança pode experimentar emoções, desejos, medos, construir novos conhecimentos do mundo que a cerca, assim, o acesso aos livros para as crianças da Educação Infantil das escolas públicas é muito importante, pois muitas crianças não têm contato com esses tipos de materiais.

Palavras-chave: Literatura, Educação Infantil, Programa Nacional Biblioteca da Escola

\section{BOOKS FOR THE FIRST CHILDHOOD: ANALYZING THE COLLECTIONS OF NATIONAL LIBRARY OF THE SCHOOL PROGRAM}

\begin{abstract}
This study aimed to understand the process of acquisition and distribution of literature books for Early Childhood Education distributed by the National Library Program of the School presenting data on the functioning and resources invested by the MEC. To do so, it was based on the research of qualitative - quantitative approach, of documental and bibliographical character. The PNBE was established in 1997 to promote access to and encourage the reading of students and teachers. During the eighteen (18) years of PNBE's existence, Early Childhood Education was contemplated in four editions (2008, 2010, 2012 and 2014), acquiring 20.998 .568 books with an investment of $\mathrm{R} \$ 96.009 .536,40$. Through the works of children's literature the child can experience emotions, desires, fears, build new knowledge of the world around him, thus, access to books for children in public schools is very important, since many children's do not have contact with these types of materials.
\end{abstract}

Keywords: Literature, Early Childhood Education, National Program of the School Library 


\section{INTRODUÇÃO}

No Brasil, desde meados da década de 1990, mais especificamente no ano de 1997, o Ministério da Educação (MEC) instituiu o Programa Nacional Biblioteca da Escola (PNBE), com a finalidade de distribuir obras literárias para alunos/as e professoras/es das escolas públicas.

O PNBE, em vigência até o ano de 2014, foi desenvolvido pelo MEC, com parceria da Secretaria de Educação Básica (SEB) e Fundo Nacional da Educação Básica (FNDE), com o intuito de distribuir obras de literatura, revistas e livros de referências para composição das bibliotecas das escolas públicas cadastradas no Censo Escolar. No decorrer de suas várias edições, o Programa foi ampliando o seu alcance, assim, a distribuição dos materiais do Programa passou a contemplar a Educação Infantil no PNBE 2008, o Ensino Médio no PNBE 2009 e a Educação de Jovens e Adultos no PNBE 2010.

Em suma, foi a partir do PNBE 2010 que todas as modalidades de ensino passaram a ser atendidas pelo Programa e houve a inclusão de outras ações específicas como: a) PNBE Especial: obras teóricas sobre necessidades especiais; b) PNBE Temático: obras de literatura que retratem o reconhecimento e a diversidade humana; c) PNBE Periódicos: revistas da área educacional; d) PNBE do Professor: obras de referências teóricas e metodológicas (BRASIL, 2009).

No ano de 2014, o PNBE completou dezoito (18) anos de funcionamento com a distribuição de quinze (15) edições do Programa, distribuindo 316.440 .303 entre livros e periódicos, com um investimento total de $\mathrm{R} \$ 1$ 1.163.462.254,86 (BRANDÃO, 2016). Por conseguinte, esses dados de investimento no PNBE, nos levam a ressaltar que $\mathrm{R} \$ 722.669 .621,29$ foram aplicados na ação principal do Programa, que era a aquisição de obras literárias e $\mathrm{R} \$ 440.792 .633,57$ foram gastos nas compras de periódicos e livros teóricos-metodológicos. Disso, concluímos que no período de 1998 a 2014, a distribuição de obras literárias teve o montante de 64\% dos recursos aplicados. 0 Gráfico 1 apresenta os valores gastos na aquisição das obras de literatura em cada modalidade de ensino.

Gráfico 1. Investimentos na aquisição das obras de literatura no período de 1998 a 2014

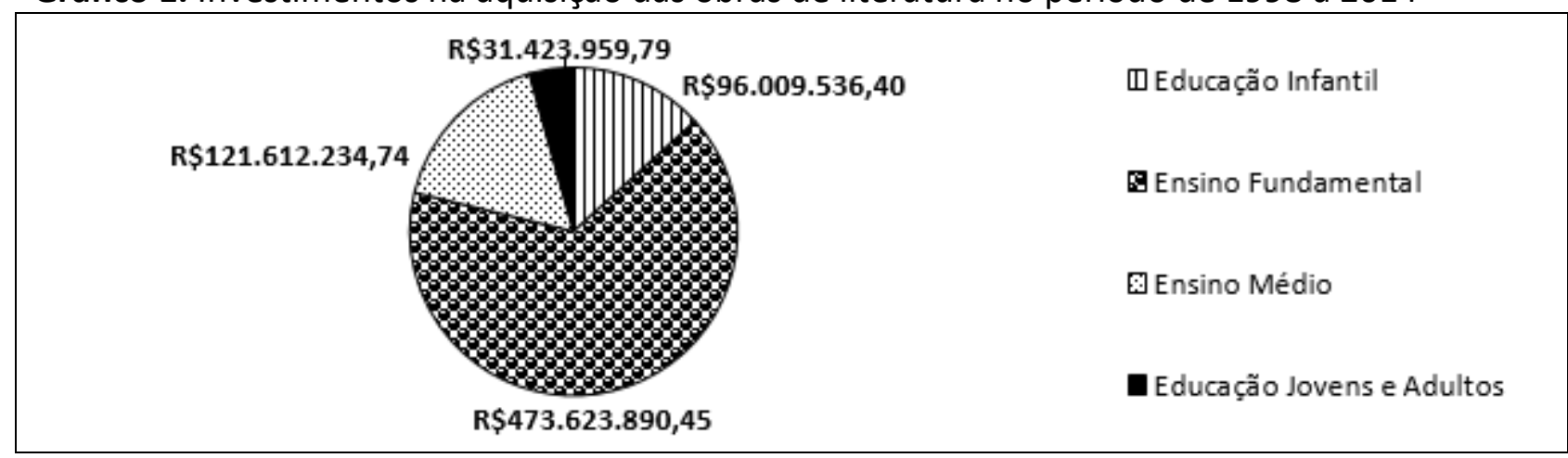

Fonte: Elaborado pelas autoras com dados de Brasil (2016)

Analisados os dados apresentados no Gráfico 1, podemos afirmar que o PNBE, na aquisição das obras de literatura, teve um investimento de 13\% para a Educação Infantil, $34 \%$ para anos iniciais e $33 \%$ para anos finais (totalizando 67\% para o Ensino Fundamental), 16\% Ensino Médio e 4\% para a Educação de Jovens e Adultos.

Reconhecida a relevância das distribuições de obras literárias para crianças, alunas/os e docentes, este trabalho toma como mote a discussão dos acervos distribuídos para a Educação Infantil, pois nos dezoito (18) anos de existência do Programa Nacional Biblioteca da Escola, a Educação Infantil foi contemplada em quatro edições (2008, 2010, 2012 e 2014), adquirindo 20.998.568 livros com um investimento de $\mathrm{R} \$ 96.009 .536,40$. Para tanto, utilizamos a pesquisa de abordagem quanti-quali, de cunho bibliográfico e documental, tendo como corpus de análise os documentos, portarias e editais dispostos no portal do FNDE. Dessa forma, esta pesquisa tem 
como objetivo compreender o processo de aquisição e distribuição dos livros de literatura para a Educação Infantil, por meio do Programa Nacional Biblioteca da Escola, apresentando dados sobre funcionamento e recursos investidos pelo MEC.

\section{O PNBE E A LITERATURA INFANTIL}

O ideal é que a criança, mesmo antes de ler, trave contato com os livros, manipule-os, aprecie as ilustrações, interprete o que está vendo à sua maneira. Isso é uma forma inteligente de lhe despertar o gosto, que depois se traduzirá pelas primeiras e definitivas leituras (NISKIER, 1999, p. 18).

A citação de Niskier será o ponto-chave para a discussão sobre o Programa Nacional Biblioteca da Escola e a literatura infantil uma vez que, a partir do trecho citado, podemos assegurar como é importante e necessário que as/os pequenas/os tenham acesso a livros de literatura no espaço escolar, em especial, porque muitas crianças só terão contato com esses tipos de materiais no ambiente educacional.

Nesse sentido, para garantir a literatura na Educação Infantil, o Programa Nacional Biblioteca da escola, a partir da edição PNBE 2008, deu início à aquisição e distribuição das obras de literatura para as crianças. Conforme Soares (2008), a inclusão da Educação Infantil no Programa demonstrou um avanço significativo, haja vista sinalizar a importância e mesmo a necessidade da presença do livro e da leitura no processo educativo da criança, antes do início da sua alfabetização formal.

O Programa Nacional Biblioteca da Escola, até o ano de 2014, completou a distribuição de quatro edições (PNBE 2008, PNBE 2010, PNBE 2012 E PNBE 2014) para a Educação Infantil. Para a aquisição das obras literárias, o PNBE passa pelas seguintes etapas: elaboração do edital, inscrições das editoras, avaliação e seleção das obras, negociação e aquisição, produção, avaliação da qualidade física das obras e distribuição.

Nos editais constam os critérios necessários para a inscrição e seleção das obras e uma das informações estabelecidas é a composição dos acervos que serão adquiridos. Os acervos devem conter títulos de diversos gêneros literários, sendo: 1) Textos em Verso: quadra, parlenda, cantiga, trava-língua, poema; 2)Textos em prosa: clássicos da literatura infantil, pequenas histórias, folclore; 3) Livros de imagens e livros de histórias em quadrinhos: obras clássicas da literatura universal 4) Livros com narrativa de palavras-chave - livros que vinculem imagens com palavras e/ou Livros de narrativas por imagens - com cores e técnicas diferenciadas como: desenho, aquarela, pintura, entre outras (BRASIL, 2016). O Quadro 1 demonstra a distribuição dos gêneros literários dos livros distribuídos para a Educação Infantil.

Quadro 1. Gêneros literários das obras do PNBE - Educação Infantil

\begin{tabular}{|c|c|c|c|c|c|c|c|c|c|}
\hline \multirow{2}{*}{ Edição do PNBE } & \multicolumn{2}{|c|}{ Verso } & \multicolumn{2}{c|}{ Prosa } & \multicolumn{2}{c|}{$\begin{array}{c}\text { Imagem/ } \\
\text { Quadrinhos }\end{array}$} & \multicolumn{2}{c|}{ Palavra Chave } & Total \\
\hline PNBE 2008 & 31 & $51 \%$ & 19 & $32 \%$ & 10 & $17 \%$ & & & 60 \\
\hline PNBE 2010 & 23 & $23 \%$ & 48 & $48 \%$ & 23 & $23 \%$ & 6 & $6 \%$ & 100 \\
\hline PNBE 2012 & 18 & $18 \%$ & 53 & $53 \%$ & 27 & $27 \%$ & 2 & $2 \%$ & 100 \\
\hline PNBE 2014 & 19 & $19 \%$ & 56 & $56 \%$ & 22 & $22 \%$ & 3 & $3 \%$ & 100 \\
\hline
\end{tabular}

Fonte: Elaborado pelas autoras com dados de Paiva (2015, p. 174)

Diante dos dados, percebemos que a categoria prosa e verso foram os gêneros literários que predominaram nos títulos adquiridos para a Educação Infantil. Paiva (2015) afirma que a prevalência pela prosa e verso se deve pela preferência do mercado escolar, pois nos catálogos das editoras são os gêneros que possuem mais livros disponibilizados para as crianças.

Sobre a diversidade de gêneros literários nas escolas, Reyes (2012) afirma que: 
Precisamos de histórias, de poemas e de toda a literatura possível na escola, não para sublinhar ideias principais, mas para favorecer uma educação sentimental. Não para identificar a moral da história, ensinamentos e valores, mas para empreendermos essa antiga tarefa do "conhece-te a ti mesmo" e "conheça os demais" (REYES, 2012, p. 28).

Nessa direção, na primeira avaliação das obras, segue o critério de inicialmente excluir os títulos que são de caráter explicitamente moralizante e didatizante. Assim, além dos acervos serem compostos por diferentes gêneros, a seleção dos livros deve seguir três critérios: qualidade textual, qualidade temática, qualidade estética das ilustrações. Segundo Paiva (2015):

É por essa razão que uma das maiores preocupações presentes nos editais do PNBE é justamente assegurar que o didatismo que ronda a relação da literatura com a educação não aconteça, razão pela qual são eliminadas do processo de seleção obras que sejam predominantemente didáticas, informativas ou de referência. A questão é ainda reforçada pela igual eliminação de obras que possuam lacunas ou espaços de preenchimento em semelhança ao livro didático, pois, além de impedir um uso coletivo, podem também conduzir a leitura do aluno para um fim pedagógico (PAIVA, 2015, p. 174 -175).

A inclusão da Educação Infantil no PNBE favoreceu a produção de livros para as crianças de 0 a 5 anos e, nesta linha de pensamento, Soares (2008) avalia como precária a produção de obras para essas idades e até mesmo o conhecimento das editoras e autores sobre o tipo de livro que é mais adequado para as crianças que ainda não estão alfabetizadas, mas que estão inseridas no mundo letrado. A distribuição dos acervos segue os critérios estabelecidos a cada ano e em cada edital. Diante disso, cabe ressaltar como ocorreu a entrega dos acervos para as escolas da Educação Infantil, isto é, no PNBE 2008 e PNBE 2010 os livros foram distribuídos para as crianças da pré-escola (4 e 5 anos), já no PNBE 2012 e PNBE 2014 foram incluídas as crianças da creche (0 a 3 anos).

No PNBE 2008, foram selecionados sessenta (60) livros para formarem três acervos. Cada acervo possuía vinte (20) obras que foram distribuídos conforme o número de crianças matriculadas nos estabelecimentos de ensino, sendo, até 150 crianças equivalentes a 1 acervo, de 151 a 300 crianças, 2 acervos e de 301 ou mais crianças, 3 acervos. Segundo Brandão (2016, p. 72), "juntamente com os livros para Educação Infantil, também foi distribuído o Guia "Literatura na infância: imagens e palavras", para que as/os professoras/es pudessem conhecer o Programa e as obras que chegaram às escolas."

Para o PNBE 2010, foram adquiridos cem (100) títulos, os quais formaram quatro acervos de vinte e cinco (25) títulos em cada. Foi entregue um acervo para escolas que tivessem até cinquenta (50) crianças, aquelas com mais de cinquenta crianças receberam dois acervos. O PNBE 2012 selecionou cem (100) obras para compor quatro acervos, com vinte e cinco (25) títulos em cada um, dois foram direcionados para as crianças de 0 a 3 anos (creche) e dois para as crianças de 4 e 5 anos (pré-escola), sendo que os estabelecimentos com até cinquenta (50) matrículas receberam um acervo, aqueles com mais de cinquenta (50), dois acervos distintos.

Por outro lado, o PNBE 2014 teve a mesma estruturação do PNBE 2012, mudando apenas o critério de atendimento, passando a entregar um acervo para escolas com até quarenta (40) crianças matriculadas e dois acervos para as que tivessem mais de quarenta (40) crianças. No PNBE 2014, juntamente com os acervos, foi entregue o Guia "PNBE na Escola: Literatura fora da caixa", com a apresentação do Programa e sugestões de atividades pedagógicas para serem desenvolvidas com cada obra distribuída. 
Ao analisar os critérios para o recebimento dos acervos nas escolas da Educação Infantil, podemos afirmar que todas as instituições de ensino que estiverem cadastradas no Censo escolar receberão, no mínimo, um acervo com vinte e cinco (25) títulos e o máximo de obras distribuídas para cada escola foram dois acervos, totalizando cinquenta (50) obras.

Compreendendo como foi determinado o quantitativo de livros que cada escola da Educação Infantil recebeu, é pertinente informar os recursos que foram gastos no processo de seleção, aquisição e distribuição das obras de literatura. O Gráfico 2 disponibiliza os investimentos em cada edição do PNBE.

Gráfico 2. Investimentos na aquisição das obras de literatura para o PNBE - Educação Infantil

\begin{tabular}{|c|c|c|}
\hline PNBE 2008 & $\begin{array}{r}\text { B 1.948.140 } \\
\text { R\$9.044.930,30 }\end{array}$ & Total de livros adquiridos \\
\hline PNBE 2010 & $\begin{array}{r}3.390 .050 \\
\mathrm{R} \$ 12.161 .043,13\end{array}$ & \\
\hline PNBE 2012 & स. 3.485 .200 & Dinvestımento total \\
\hline PNBE 2014 & $12.1 / 3.1 / 8$ & $.537 .660,06$ \\
\hline
\end{tabular}

Fonte: Elaborado pelas autoras com dados de Brasil (2016)

Desde que o PNBE iniciou a distribuição das obras de literatura para a Educação Infantil, houve um aumento significativo na quantidade de exemplares adquiridos pelo Programa. Conforme os dados apresentados, percebemos que a maior ampliação de aquisição e investimento ocorreu no PNBE 2014, pois no atendimento para a creche (0 a 3 anos) distribuiu 4.209.150 livros para 32.820 escolas, tendo investido $\mathrm{R} \$ 17.730 .630,46$ e, para crianças da préescola (4 e 5anos) foram distribuídos 7.966 .028 livros beneficiando 79.949 escolas, totalizando um investimento de $\mathrm{R} \$ 32.807 .029,60$. O Quadro 2 demonstra o investimento total referentes às quatro edições do PNBE para a Educação Infantil.

Quadro 2. Panorama total das edições do PNBE para a Educação Infantil (2008 a 2014)

\begin{tabular}{|c|c|}
\hline \multicolumn{2}{|c|}{ PNBE - EDUCAÇÃO INFANTIL } \\
\hline Total de exemplares & Recursos gastos \\
\hline 20.998 .568 & $\mathrm{R} \$ 96.369 .536,40$ \\
\hline
\end{tabular}

Fonte: Elaborado pelas autoras com dados de Brasil (2016)

Diante das informações apresentadas, fica nítida a importância do Programa Nacional Biblioteca da Escola no contexto da política pública de leitura, porém, várias pesquisas têm demonstrado que o PNBE possui sua consolidação no aspecto de distribuição das obras e que é necessário o investimento na divulgação e na formação das/dos professoras/es e mediadoras/es. Entretanto, tal afirmação não corrobora com a perspectiva de finalização do PNBE, uma vez que um dos problemas dos programas governamentais é sempre a descontinuidade das ações já implementadas.

\section{ALGUMAS CONSIDERAÇÕES}

O Programa Nacional Biblioteca da Escola, iniciou a primeira distribuição de obras literárias no PNBE 1998 e, após dez (10) anos, no PNBE 2008, foram incluídos os livros de literatura para as crianças de 0 a 5 anos. Esta ação no PNBE pode ser considerada como um avanço significativo para 
a Educação Infantil, porque representou a importância da disposição de livros de literatura infantil para as crianças, as quais, mesmo sem estarem no processo da alfabetização formal, podem e devem ter acesso ao objeto livro.

Cabe ressaltar que apenas a distribuição das obras do PNBE não é suficiente para a promoção do acesso dos livros para o trabalho literário com as crianças, ainda é necessário a "real" utilização dessas obras nos espaços escolares. Entretanto, a distribuição das obras literárias promove a ideia da formalização da biblioteca ou espaços de leitura dentro das salas, incentivando o planejamento de ações no âmbito estadual, municipal e institucional. Destacamos que é importante compreender o processo de aquisição e distribuição dos livros de literatura para a Educação Infantil distribuídos pelo Programa Nacional Biblioteca da Escola, a fim de que os dados contribuam para o embasamento das discussões e divulgações das ações do PNBE entre profissionais da educação e pesquisadoras/es.

Por fim, parece-nos ainda coerente afirmar que numa perspectiva de valores na formação de leitores é preciso a continuidade do PNBE, sua extinção se torna um retrocesso para as políticas públicas de incentivo à leitura. O que se faz necessário é a restruturação do Programa visando a implementações de ações para promoção da formação das/os professoras/es e mediadoras/es de leitura.

\section{REFERÊNCIAS}

BRANDÃO, Claudia Leite. PNBE do Professor: Usos e desusos. Dissertação de Mestrado (Mestrado em Educação). Universidade Federal de Mato Grosso. Rondonópolis, 2016.

\section{BRASIL. Fundo Nacional de Desenvolvimento da Educação. Programa Nacional Biblioteca da}

Escola. Disponível em: <http://www.fnde.gov.br/programas/biblioteca-da-escola/biblioteca-daescola-apresentacao>. Acesso em: 24 de jan. de 2016.

NISKIER, Arnaldo. "Um País se faz com homens e livros". In: PRADO, Jason. (org.). A formação do leitor: pontos de vista. Rio de Janeiro: Argus, 1999, p. 17 -24.

PAIVA, Aparecida. PNBE: seleção, distribuição, circulação e usos de livros de literatura na Educação Infantil: uma política em (re)construção. In: Brasil. Literatura na educação infantil: acervos, espaços e mediações / Monica Correia Baptista ... [et al.], org. - Brasília: MEC, 2015, p. 157 -180.

REYES, Yolanda. Ler e brincar, tecer e cantar - Literatura, escrita e educação. Tradução: Rodrigo Petrônio; São Paulo: Editora Pulo do Gato, 2012.

SOARES, Magda. Livros para a Educação Infantil: a perspectiva editorial. In: PAIVA, Aparecida; SOARES, Magda (orgs.). Literatura Infantil: políticas e concepções. Belo Horizonte: Autêntica Editora, 2008, p. $21-34$. 